\title{
PRODUTIVIDADE E COMPOSIÇÃO QUÍMICA DE GRAMÍNEAS TEMPERADAS NA CIDADE DE ARAPONGAS-PR.
}

Fabiola Cristine de Almeida Rego Grecco ${ }^{1}$, Luiz Fernando Coelho Cunha Filho ${ }^{1}$, Werner Okano ${ }^{1}$, Luiz Cesar Da Silva ${ }^{1}$, Marilice Zundt ${ }^{2}$, Luis Carlos Vianna ${ }^{2}$

${ }^{1}$ Docente do Curso de Medicina Veterinária - Área: Forragicultura, UNOPAR, Arapongas/PR. E-mail: fabiola_rego@yahoo.com.br

${ }^{2}$ Docentes do Curso de Medicina Veterinária e Zootecnia da UNOESTE, Presidente Prudente/SP.

\section{RESUMO}

O objetivo deste trabalho foi avaliar quatro genótipos de gramíneas temperadas na cidade de Arapongas, PR. O plantio foi realizado em abril de 2007, utilizando as seguintes espécies: Aveia preta (Avena strigosa Schreb) comum, Aveia preta (Avena strigosa Schreb) IAPAR 61, Aveia branca (Avena sativa L.) IPR 126 e Azevem (Lolium multiflorum). O plantio foi feito em parcelas, totalizando 12 repetições para cada espécie. A produção de matéria seca por hectare (MS ha ${ }^{-1}$ ) para Aveia preta, Aveia IAPAR 61, Aveia IPR126 e Azevem foram respectivamente: 1,$36 ; 0,86 ; 1,17$ e 0,67 ton de $\mathrm{MS} \mathrm{ha}^{-1}$. Na região avaliada, em condições de estiagem no período de implantação, a aveia preta comum foi mais produtiva que as demais; entretanto com relação à composição química, a aveia preta IAPAR 61 se sobressaiu com relação à Aveia preta comum, apresentando maior teor de proteína bruta (PB) presente na MS e também menor teor de PB na porção de fibra em detergente neutro (FDN). A aveia branca IPR126, apesar da pequena quantidade de estudos, tem apresentado bons resultados, em muitas regiões até superiores à aveia preta comum.

Palavras-chave: aveia preta; aveia branca; azevem; proteína bruta; fibra em detergente neutro.

YIELD AND CHEMICAL COMPOSITION OF TEMPERATE GRASSES IN ARAPONGAS-PR.

\begin{abstract}
The objective of this work was to evaluate four genotypes of temperate grasses in Arapongas, PR. The plantation was realized on 2007 April, using the follow species: black oat common (Avena strigosa Schreb), black oat (Avena strigosa Schreb) IAPAR 61, white oat (Avena sativa L.) IPR 126 and Italian ryegrass (Lolium multiflorum Lam.). The plantation was realized in paddocks, aimed 12 repetitions for each specie. The production of dry matter/ha (DM/ha) to black oat, black oat IAPAR 61, white oat IPR126 and Azevem were respectively: 1,$36 ; 0,86 ; 1,17$ e 0,67 ton of $\mathrm{DM} / \mathrm{ha}$. In the region evaluated, under conditions of drought during the deployment, the black oat common was more productive than others, but in relation to chemical composition, Black oat IAPAR 61 stood out with respect to the Black oat common, with higher levels of crude protein (CP) present in MS and also lower content of CP withheld on neutral detergent fiber (NDF) portion. The IPR126 oat, despite the small number of studies has demonstrated good results in many areas better to the common oat.
\end{abstract}

Keywords: oat black; oat white; Italian ryegrass; rude protein; neutral detergent fiber. 


\section{INTRODUÇÃO}

O uso de gramíneas forrageiras de inverno como fonte de alimentação para ruminantes é uma excelente alternativa no que se diz respeito à qualidade final da dieta que essas fornecem aos animais. $O$ uso de forrageiras anuais de inverno constitui uma importante alternativa para rotação com as culturas de verão, amenizando assim o vazio forrageiro durante a estação fria. Sendo que entre as forrageiras de inverno disponíveis, destaca-se a aveia forrageira, tanto por sua produtividade quanto pelo seu valor nutritivo. Além disso, a aveia forrageira pode ser utilizada sob pastoreio, sendo consumida diretamente no campo, ou sob corte, através do fornecimento imediato da matéria verde no cocho.

Apesar dos benefícios comprovados das espécies de gramíneas de inverno, sabe-se que as mesmas são exigentes com relação às características de clima e fertilidade de solo, muitas vezes não expressando todo seu potencial de produção em determinadas regiões. A produção de matéria seca de gramíneas de inverno, de modo geral pode ser elevada, mas varia, entre outros fatores, conforme a região e o cultivar utilizado, sendo que para a recomendação de seu uso deve-se primeiramente identificar quais se adaptam melhor à determinada região (ALVIM; COSER, 2000).

O cultivar IAPAR 61 é uma aveia preta (Avena strigosa Schreb) lançada pelo IAPAR no ano de 1993, enquanto a IPR-126 é uma aveia branca (Avena sativa L.) lançada em 2006 e tem como característica principal possuir um ciclo tardio e um bom rendimento em matéria seca, sendo também indicada para cobertura de solo, ou seja, é considerada uma espécie de dupla aptidão: pastagem e cobertura do solo. Para regiões mais quentes como o norte do Paraná e sul do estado de São Paulo, a aveia preta (Avena strigosa) tem sido a mais utilizada, devido ao alto rendimento de forragem, maior resistência a doenças e ao pisoteio (FLOSS, 1995).

O azevem anual (Lolium multiflorum Lam) pode ser utilizado para pastejo, feno, silagem présecada, além do fornecimento verde no cocho. Entretanto esta espécie possui desenvolvimento inicial lento e é muito utilizada em consorciações com outras espécies (CANTO et al., 1999).

Das forrageiras de inverno utilizadas, a aveia forrageira é de grande importância na alimentação de ruminantes, e segundo Reis et al. (1993), existe grande variação entre as espécies, cultivares, variedades e linhagens do gênero. Essa variação pode estar relacionada à idade de corte, à precocidade, à tolerância a seca e às características de solo, entre outras (FONTANELLI et al., 1993).

A produtividade e qualidade das espécies cultivadas no inverno também variam conforme o ano, devido às grandes variações que ocorrem o clima de um ano para o outro. Em ensaio de canteiros realizado na região de Maringá observou-se que a produtividade de diversas cultivares de aveia analisadas variou de 2,3 a 3,1 toneladas de matéria seca por hectare (BERALDO et al.,1997). Em outro ensaio ocorrido na mesma região, porém no ano seguinte, a produtividade variou de 2,3 a 5,3 toneladas de matéria seca por hectare, mostrando que a utilização de uma espécie na mesma região apresenta diferentes resultados, conforme as condições climáticas e de manejo.

A qualidade e a quantidade de matéria seca a ser produzida pelas forrageiras de inverno são determinadas, entre outros fatores, pelo manejo ao qual são submetidas na fase de produção, como irrigação, fertilização, altura e freqüência de corte utilizados (ALVIM; COSER, 2000).

O objetivo desta pesquisa foi avaliar a produtividade e composição bromatológica de diferentes genótipos de gramíneas temperadas 
na região de Arapongas, submetidas às condições naturais do clima da região, sem intervenções de irrigação. As espécies avaliadas foram as seguintes: aveia preta (Avena strigosa Schreb) comum, aveia preta (Avena strigosa Schreb) IAPAR 61, aveia branca (Avena sativa L.) IPR 126 e azevem (Lolium multiflorum).

\section{MATERIAL E MÉTODOS}

O experimento foi realizado no Campus da Universidade Norte do Paraná (UNOPAR), na cidade de Arapongas, latitude $23^{\circ} 25^{\prime}$ Sul, longitude $51^{\circ} 26^{\prime}$ e altitude 816,36 m acima do nível do mar. O clima da cidade é classificado como subtropical úmido, com temperaturas oscilando entre $8^{\circ} \mathrm{C}$ (mínima) e $32^{\circ} \mathrm{C}$ (máxima).

Foram avaliados quatro genótipos de gramíneas temperadas: Aveia preta comum (Avena strigosa Schreb), Aveia preta cv. IAPAR 61 (Avena strigosa Schreb cv. IAPAR 61), Aveia branca cv. IPR 126 (Avena sativa L.) e Azevem perene (Lolium multiflorum). As unidades experimentais (canteiros) foram parcelas de $3 \mathrm{x}$ $0,6 \mathrm{~m}$, contendo quatro linhas distanciadas de 20 $\mathrm{cm}$. As linhas foram marcadas superficialmente com sulcador manual. Ao total foram feitos 48 canteiros, sendo 12 repetições para cada genótipo, que foram distribuídos em três blocos de 16 canteiros cada.

O plantio foi realizado no dia 26 de abril de 2007. As sementes utilizadas apresentavam em média $90 \%$ de poder de germinação, e foram fornecidas pelo IAPAR (Instituto Agronômico do Paraná). Para a Aveia preta comum e a IAPAR 61 foi utilizada a recomendação de $62 \mathrm{~kg}$ de sementes por ha; para a Aveia branca IPR 126, $75 \mathrm{~kg}$ de sementes por há, para o Azevem, $50 \mathrm{~kg}$ de sementes por ha. Os dados de temperatura e precipitação estão nas Figuras 1 e 2.

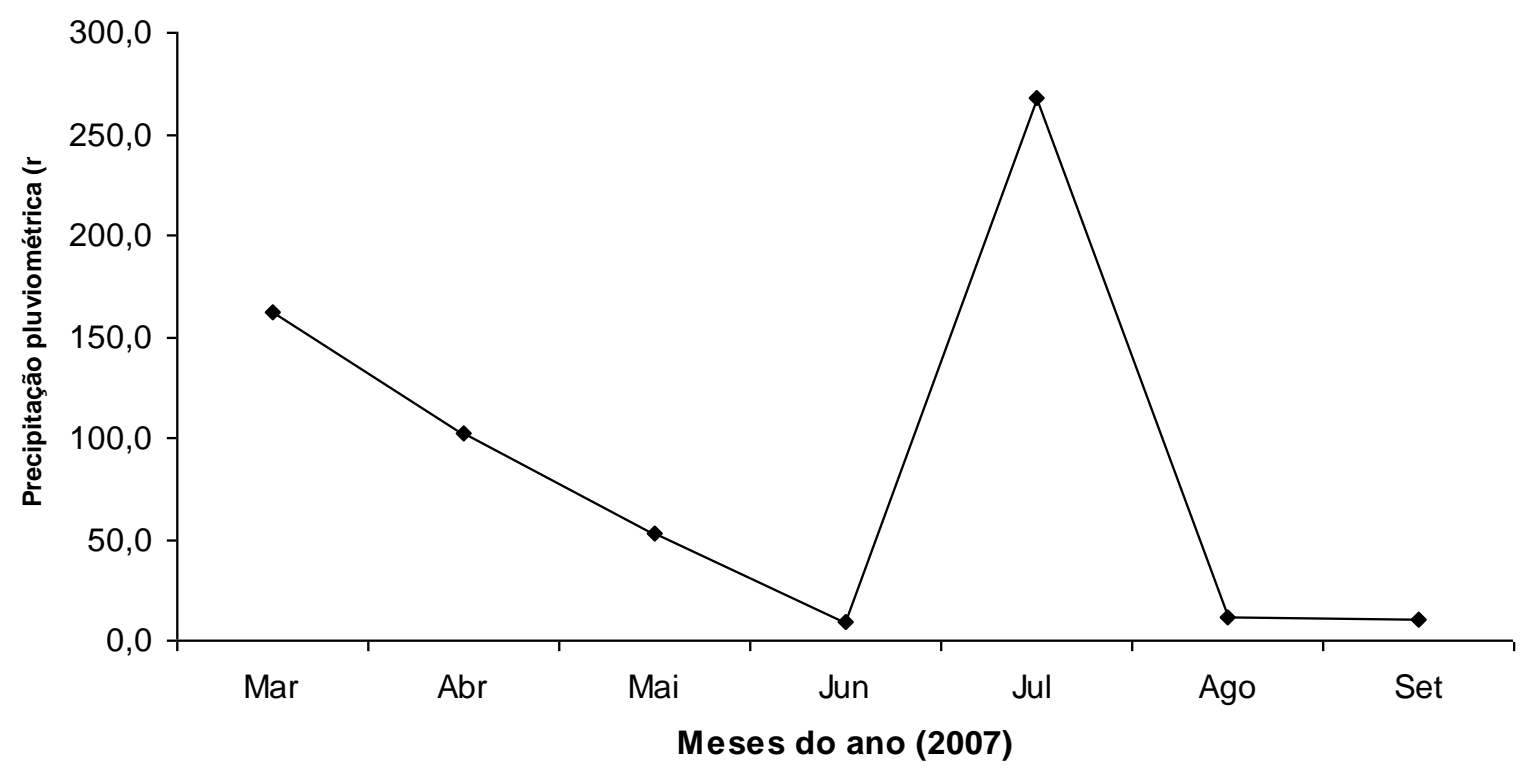

Figura 1. Dados médios mensais de precipitação pluviométrica $(\mathrm{mm})$ no período de março a setembro de 2007 (Estação meteorológica - prefeitura municipal de Arapongas) 


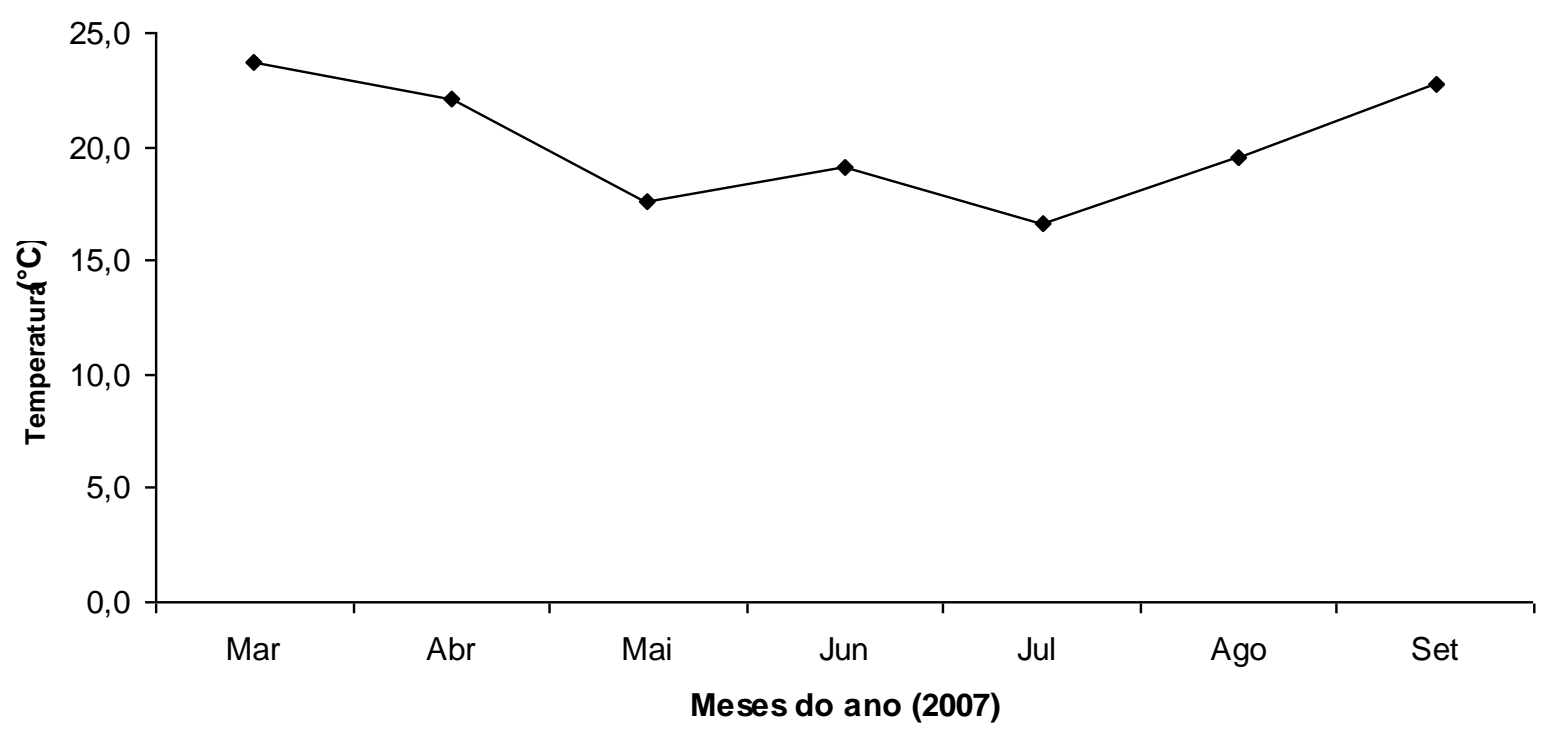

Figura 2. Dados médios mensais de temperatura $\left({ }^{\circ} \mathrm{C}\right)$, no período de março a setembro de 2007.

$\mathrm{Na}$ ocasião do plantio foi realizada uma adubação básica com o equivalente a $90 \mathrm{~kg}$ de $\mathrm{P}_{2} \mathrm{O}_{5} /$ ha, utilizando o adubo super simples $(18 \%$ de $\left.\mathrm{P}_{2} \mathrm{O}_{5}\right)$.

O corte foi realizado três meses após o plantio, no dia 31 de julho de 2007. Não foi realizada nenhuma irrigação artificial, para observar o crescimento das espécies nas condições reais existentes na região. Neste período de crescimento também não foi realizada nenhuma adubação nitrogenada nos canteiros.

O corte foi realizado a $10 \mathrm{~cm}$ do nível do solo, com o uso de tesoura de jardinagem. As parcelas foram cortadas integralmente, ou seja, todas as linhas do canteiro. Após o corte as amostras foram acondicionadas em sacos plásticos e encaminhadas imediatamente ao laboratório de Bromatologia da UNOPAR, para a pesagem da massa verde das espécies. Após essa pesagem separou-se uma sub amostra, que foi previamente pesada e colocada em estufa a 55드 durante três dias para a determinação da massa seca das mesmas.

As variáveis de produção obtidas foram: produção de matéria verde (ton $\mathrm{MV}_{\mathrm{ha}}{ }^{-1}$ ), teor de matéria seca (\%) e produção de matéria seca por ha (ton $\mathrm{MS} \mathrm{ha}^{-1}$ ).

Foram realizadas também as análises bromatológicas quanto ao teor de matéria seca definitiva (MS, \%), teor de proteína bruta (PB, \%), teor de fibra em detergente neutro (FDN, \%), PB do FDN (PBFDN, \%) e cinzas (CINZAS, \%) segundo metodologias descritas por Silva (1990).

As variáveis foram analisadas pelo programa estatístico SAEG (1997), com o uso do teste Tukey para um nível de $5 \%$ de probabilidade.

\section{RESULTADOS E DISCUSSÃO}

A produtividade das gramíneas temperadas está descrita na Tabela 1. Os resultados são referentes à média de produção de cada espécie, sendo 9 canteiros para cada uma delas.

Com relação à produção de matéria verde destacaram-se a aveia preta comum e a aveia branca IPR 126, com 6,24 e 5,15 ton MV ha ${ }^{-1}$, conforme Tabela 1. 
Tabela 1. Produtividade de gramíneas temperadas, na cidade de Arapongas/PR, no ano de 2007.

\begin{tabular}{crcc}
\hline Gramínea & $\begin{array}{c}\text { Produção MV } \\
(\text { ton MV ha-1 }\end{array}$ & $\begin{array}{c}\text { Teor MS } \\
(\%)\end{array}$ & $\begin{array}{c}\text { Produção MS } \\
\text { (ton MS ha }{ }^{-1}\end{array}$ \\
\hline Aveia preta comum & $6,24 \mathrm{a}$ & $22,00 \mathrm{a}$ & $1,36 \mathrm{a}$ \\
Aveia preta IAPAR61 & $4,06 \mathrm{~b}$ & $22,00 \mathrm{a}$ & $0,86 \mathrm{~b}$ \\
Aveia branca IPR126 & $5,15 \mathrm{a}$ & $24,00 \mathrm{a}$ & $1,17 \mathrm{a}$ \\
Azevem & $2,49 \mathrm{~b}$ & $30,00 \mathrm{a}$ & $0,67 \mathrm{~b}$ \\
\hline
\end{tabular}

Os teores de MS não variaram entre as espécies, e a produção de MS seguiu o mesmo padrão da produção de matéria verde (Tabela 1). A produção de MS do cultivar IAPAR 61 (0,86 ton $\mathrm{MS} \mathrm{ha}^{-1}$ ) se assemelhou ao ensaio realizado na região de Maringá com a mesma cultivar, que produziu 1,09 ton de $\mathrm{MS} \mathrm{ha}^{-1}$ (CECATO et al.,2001).

A composição bromatológica das espécies está descrita na Tabela 2.

Tabela 2. Médias dos teores de matéria seca definitiva (MS, \%), de proteína bruta (PB,\%), de fibra em detergente neutro (FDN,\%), da PB do FDN (PBFDN,\%).

\begin{tabular}{lccccc}
\hline \multicolumn{1}{c}{ Gramíneas } & MS & PB & FDN & PBFDN & \multicolumn{2}{c}{ Cinzas } \\
\cline { 2 - 5 } & $(\%)$ & $(\%)$ & $(\%)$ & $(\%)$ & $(\%)$ \\
\hline Aveia preta comum & $83,5 \mathrm{a}$ & $17,24 \mathrm{a}$ & $52,88 \mathrm{a}$ & $6,02 \mathrm{a}$ & $0,51 \mathrm{a}$ \\
Aveia preta IAPAR61 & $85,9 \mathrm{a}$ & $19,68 \mathrm{a}$ & $52,89 \mathrm{a}$ & $1,76 \mathrm{~b}$ & $0,49 \mathrm{a}$ \\
Aveia branca IPR126 & $85,5 \mathrm{a}$ & $17,36 \mathrm{a}$ & $46,25 \mathrm{~b}$ & $1,67 \mathrm{~b}$ & $0,44 \mathrm{a}$ \\
Azevem & $84,4 \mathrm{a}$ & $16,92 \mathrm{a}$ & $49,92 \mathrm{a}$ & $1,82 \mathrm{~b}$ & $0,46 \mathrm{a}$ \\
\hline
\end{tabular}

Os teores de MS foram semelhantes entre as espécies $(p>0,05)$. Da mesma forma, os teores de PB não sofreram variação estatística entre as espécies $(P>0,05)$ e para a aveia preta comum (17,24\%) e azevem (16,92\%) se assemelharam aos teores observados por Rodrigues, Coelho e Reis (2002). O teor de FDN foi significativamente superior $(p<0,05)$ para a aveia preta comum e IAPAR 61. Já o teor de PB do FDN foi superior somente para a aveia preta comum em relação às outras duas espécies. Os teores de cinzas foram 0,$51 ; 0,49$ e 0,44 para a aveia preta comum, IAPAR61 e aveia branca IPR 126.

Os dados apresentados demonstraram superioridade da produção da aveia preta comum em relação a IAPAR 61 e ao azevem $(p<0,05)$, entretanto esta espécie mostrou-se com produções equivalentes à aveia branca IPR126 $(p>0,05)$. Em outras regiões têm sido observados resultados superiores da aveia preta IAPAR 61 em relação à aveia preta comum, devido principalmente, ao seu ciclo mais longo (NORO et al., 2003).

De acordo com Keplin (1996), o azevem é uma cultura mais exigente quanto à umidade que outras espécies temperadas, entretanto, apesar desta característica, no presente trabalho sua produtividade se equiparou à da aveia preta IAPAR 61 (Tabela 1). No Rio Grande do Sul, esta gramínea é comumente usada, tanto em cultivo solteiro ou associada com a aveia preta comum ou a cultivar IAPAR 61; e tem demonstrado ótimos resultados de desempenho animal quando utilizadas sob pastejo (MACARI et al., 2006).

Para a região Norte do Paraná, a aveia preta IAPAR 61 chegou a produzir 4,2 ton MS ha-1 durante todo o ciclo, quando fertilizada com $90 \mathrm{~kg}$ N/ha (CECATO et al., 1998). As doses de nitrogênio utilizadas e as condições climáticas na 
ocasião do cultivo são os principais responsáveis pelas diferenças encontradas na produtividade. No presente trabalho, além das condições desfavoráveis de temperatura e precipitação ocorridas no período, não se realizou a adubação nitrogenada, mas apenas a adubação fosfatada no plantio.

Para a região Noroeste do Paraná, Grise et al. (2002) verificaram melhores resultados ao usar a mistura de aveia preta IAPAR 61 e ervilha forrageira como alternativa para o período de escassez de forragem.

Os genótipos de gramíneas temperadas são muito sensíveis às condições climáticas, principalmente a precipitação. Provavelmente a falta de precipitação no período logo após o plantio (maio e junho) prejudicou fortemente 0 desenvolvimento inicial das plântulas, o que levou à baixa produtividade de todas as espécies avaliadas. De junho em diante as médias de precipitação foram elevadas, entretanto mesmo assim não ocorreu a rebrota das espécies, provavelmente pelo debilitado crescimento inicial.

Os teores de PB da IAPAR 61 (19,68\%) se assemelharam às observações feitas por Cecato et al. (2001), que relataram teores médios de 20,61\%; em avaliações na região de Maringá. A aveia preta comum e a branca IPR126 apresentaram 17,24 e $17,36 \%$ de PB, respectivamente.

Os teores de FDN variaram de 46,25 a $52,89 \%$ entre os genótipos, conforme a Tabela 2 . Esses resultados quando comparados a relatos em diversas cultivares de aveias preta e branca podem ser considerados normais e corroboram com outros autores (CECATO et al., 2001).

Os teores de cinzas foram 0,51 e 0,49 (aveia preta comum e IAPAR 61, respectivamente) e 0,44 para a aveia branca IPR126. A aveia branca IPR126, apesar da pequena quantidade de estudos sobre seu comportamento produtivo, vem demonstrando bons resultados, em muitas regiões até superiores à aveia preta comum.

O teor de PB do FDN, que é considerada como a porção da PB que é indigestível para o animal, teve o maior valor para a aveia preta comum $(6,02 \%)$, seguida pela aveia branca $(1,67 \%)$ e aveia preta IAPAR61 $(1,76 \%)$.

\section{CONCLUSÕES}

$\mathrm{Na}$ região avaliada, em condições de estiagem no período de implantação, a aveia preta comum foi mais produtiva que as demais; entretanto com relação à composição química, a aveia preta IAPAR 61 se sobressaiu com relação à aveia preta comum, apresentando maior teor de PB presente na MS e também menor teor de PB retido na porção de fibra em detergente neutro.

\section{AGRADECIMENTOS}

Instituto Agronômico do Paraná - IAPAR - pelo fornecimento das sementes e pelo apoio técnico.

\section{REFERÊNCIAS}

ALVIM, M.J. Produção e utilização de forrageiras de inverno aveia e azevem. Curso de pecuária leiteira. EMBRAPA, Documento 42, 28 p. 1990.

ALVIM, M. J.; CÓSER, A C. Aveia e Azevem anual: Recursos forrageiros para a época seca. IN: Pastagens para Gado de Leite em regiões de influência da Mata Atlântica. Coronel Pacheco: EMBRAPA. p. 83-107, 2000.

BERALDO, J.A.; CECATO, U.; SÁ, J.P.G.; DAMASCENO, J.C.; JOBIN, C.C. Avaliação de cultivares e linhagens de aveia preta (Avena strigosa Schereb). In: REUNIÃO DA SOCIEDADE BRASILEIRA DE ZOOTECNIA, 34, 1997, Juiz de Fora. Anais... Juiz de Fora: SBZ, v.2. 1997. p. 7779.

CANTO, M. W. ; MO O J E N, E.L.; C A R V A L H O, P. C. de 
F.; SIL V A, J.H. S. Produção de cordeiros em pastagem de azevém e trevobranco sob diferentes níveis de resíduos de forragem. Pesquisa Agropecuária Brasileira, v.34, n.2, p.309-316, 1999.

CECATO, U.; SARTI, L.L.; SAKAGUTI, E.S.; DAMASCENO, J.C.; REZENDE, R. ; SANTOS,

G.T. Avaliação de cultivares e linhagens de aveia (Avenna spp.). Acta Scientiarum, v.20, n.3, p. 347-354, 1998.

CECATO, U.; RÊGO, F.C.A.; GOMES, J.A.N.; CANTO, M.W. ; JOBIM, C.C.C; CONEGLIAN, S. ; MOREIRA, F.B. Produção e composição química em cultivares e linhagens de aveia (Avena spp). Acta Scientiarum. v. 23, n. 4, p. 775-780, 2001.

FLOSS, E.L. Manejo forrageiro da aveia (Avena sp) e azevém (Lolium sp). In: Simpósio sobre Manejo da Pastagem, 9, 1988, Piracicaba. Anais... Piracicaba: FEALQ, 1995. p. 191-228.

GRISE, M.M.; CECATO, U.; MORAES, A.; FACCIO, P.C.C.; CANTO, M.W.; JOBIM, C.C.; RODRIGUES, A.M. Avaliação do desempenho animal e do pasto na mistura aveia IAPAR 61 (Avena strigosa Schreb) e ervilha forrageira (Pisum arvense L.) manejada em diferentes alturas. Revista Brasileira de Zootecnia, v.31, n.3, p.1085-1091, 2002. http://dx.doi.org/10.1590/S1516-

\section{$\underline{35982002000500004}$}

MACARI, S.; ROCHA, M.G.; RESTLE, J.; PILAU, A.; FREITAS, F.K.; NEVES, F.P. Avaliação da mistura de cultivares de aveia preta (Avena strigosa Schreb) com azevem (Lolium multiflorum Lam.) sob pastejo. Ciência Rural, v. 36, n. 3, p. 910-915, 2006.

NORO, G.; SCHEFFER-BASSO, S.M.; FONTANELI, R.S.; ANDREATTA, E. Gramíneas anuais de inverno para produção de forragem: avaliação preliminar de cultivares. Agrociência, v.7, n.1, p. 35-40, 2003.
REIS, R. A.; RODRIGUES, L.R.A.; COAN, O.; VILLAÇA, M. Produção e qualidade da forragem de aveia (Avena spp). Revista da Sociedade Brasileira de Zootecnia, v.22, n.1, p. 99-108, 1993.

RODRIGUES, R.C.; COELHO, R.W.; REIS, J.C. Rendimento de forragem e composição química de cinco gramíneas de estação fria. Comunicado Técnico, 77. Pelotas: EMBRAPA, 2002.

SILVA, D.J. Análise de Alimentos (Métodos Químicos e Biológicos). 2 ed. Viçosa: Universidade Federal de Viçosa, 1990, 165 p.

UNIVERSIDADE FEDERAL DE VIÇOSA - UFV. SAEG - Sistema de análises estatísticas e genéticas. Versão 5.0, Viçosa, MG: 1993. 